\title{
Optimization of an Indirect Enzymatic Method for the Simultaneous Analysis of 3-MCPD, 2-MCPD, and Glycidyl Esters in Edible Oils
}

Kazuo Koyama ${ }^{1 *}$, Kinuko Miyazaki ${ }^{1}$, Kousuke Abe $^{2}$, Keiich Ikuta ${ }^{3}$, Yoshitsugu Egawa ${ }^{4}$, Tadashi Kitta ${ }^{5}$, Hirotsugu Kido ${ }^{6}$, Takashi Sano ${ }^{7}$, Yukinari Takahashi ${ }^{8}$, Toru Nezu', Hidenori Nohara ${ }^{10}$, Takashi Miyashita ${ }^{11}$, Hiroshi Yada ${ }^{12}$, Kumiko Yamazaki ${ }^{13}$ and Yomi Watanabe ${ }^{14}$

\footnotetext{
${ }^{1}$ Central Research \& Development Institute, House Foods Group Inc. (1-4, Takanodai, Yotsukaido, Chiba 284-0033, JAPAN)

${ }^{2}$ Analysis \& Assessment, Central Research Laboratory, The Nisshin OilliO Group, Ltd. (1, Shinmei-cho, Yokosuka 239-0832, JAPAN)

${ }^{3}$ Analytical Technical Laboratory, Japan Oilstuff Inspectors Corp. (1-2-34, Nagataminami,Minami-Ku, Yokohama 232-0073, JAPAN)

${ }^{4}$ Analytical Center for Food Safety, Quality Assurance Department, Fuji Oil Co., Ltd. (1, Sumiyoshi-cho, Izumisano, Osaka 598-8540, JAPAN)

${ }^{5}$ Japan Frozen Foods Inspection Corp. (2-13-45, Fukuura, Kanazawa-ku, Yokohama 236-0004, JAPAN)

${ }^{6}$ Japan Association for Inspection and Investigation of Foods Including Fats and Oils (3-27-8, Nihonbashi-hamacho, Chuo-ku, Tokyo 103-0007, JAPAN)

${ }^{7}$ Fundamental Research Laboratory, J-Oil Mills Inc. (7-41, Dikoku-cho, Tsurumi-ku, Yokohama 230-0053, JAPAN)

${ }^{8}$ Analytical and Technological Solution Service, House Food Analytical Laboratory Inc. (1-4, Takanodai, Yotsukaido, Chiba 284-0033, JAPAN)

${ }^{9}$ Food Development Laboratory, ADEKA Corp. (7-2-34, Higashiogu, Arakawa-ku, Tokyo 116-8553, JAPAN)

${ }^{10}$ Health Care Food Research Laboratories, Kao Corp. (2-1-3, Bunka, Sumida-ku, Tokyo 131-8501, JAPAN)

${ }_{11}^{11}$ Quality Assurance Div., Kewpie Corp. (2-5-7, Senkawa-cho,Chohu, Tokyo 182-0002, JAPAN)

${ }^{12}$ National Food Research Institute (NFRI), National Agriculture and Food Research Organization (NARO) (2-1-12, Kannon-dai, Tsukuba, Ibaraki 305-8642, JAPAN)

${ }^{13}$ Japan Food Research Laboratories, Saito Laboratory (7-4-41, Saitoasagi, Ibaraki, Osaka 567-0085, JAPAN)

${ }^{14}$ Osaka Municipal Technical Research Institute (1-6-50, Morinomiya, Joto-ku, Osaka 536-8553, JAPAN)
}

\begin{abstract}
We developed a novel, indirect enzymatic method for the analysis of fatty acid esters of 3-monochloro-1,2-propanediol (3-MCPD), 2-monochloro-1,3-propanediol (2-MCPD), and glycidol (Gly) in edible oils and fats. Using this method, the ester analytes were rapidly cleavaged by Candida rugosa lipase at room temperature for $0.5 \mathrm{~h}$. As a result of the simultaneous hydrolysis and bromination steps, 3-MCPD esters, 2-MCPD esters, and glycidyl esters were converted to free 3-MCPD, 2-MCPD, and 3-monobromo1,2-propanediol (3-MBPD), respectively. After the addition of internal standards, the mixtures were washed with hexane, derivatized with phenylboronic acid, and analyzed by gas chromatography-mass spectrometer (GC-MS). The analytical method was evaluated in preliminary and feasibility studies performed by 13 laboratories. The preliminary study from 4 laboratories showed the reproducibility $\left(\mathrm{RSD}_{\mathrm{R}}\right)$ of $<10 \%$ and recoveries in the range of $102-111 \%$ for the spiked 3-MCPD and 2-MCPD in extra virgin olive (EVO) oil, semi-solid palm oil, and solid palm oil. However, the $\mathbf{R S D}_{\mathrm{R}}$ and recoveries of Gly in the palm oil samples were not satisfactory. The Gly content of refrigerated palm oil samples decreased whereas the samples at room temperature were stable for three months, and this may be due to the depletion of Gly during cold storage. The feasibility studies performed by all 13 laboratories were conducted based on modifications of the shaking conditions for ester cleavage, the conditions of Gly bromination, and the removal of gel formed by residual lipase. Satisfactory $\mathrm{RSD}_{\mathrm{R}}$ were obtained for EVO oil samples spiked with standard esters $(4.4 \%$ for 3-MCPD, $11.2 \%$ for $2-M C P D$, and $6.6 \%$ for Gly).
\end{abstract}

Key words: indirect enzymatic method, lipase, 3-MCPD, 2-MCPD, glycidol

\footnotetext{
*Correspondence to: Kazuo Koyama, Central Research \& Development Institute, House Foods Group Inc., 1-4, Takanodai, Yotsukaido, Chiba 284-0033, JAPAN

E-mail: k-koyama@ housefoods.co.jp

Accepted June 28, 2015 (received for review April 28, 2015)

Journal of Oleo Science ISSN 1345-8957 print / ISSN 1347-3352 online

http://www.jstage.jst.go.jp/browse/jos/ http://mc.manusriptcentral.com/jjocs
} 


\section{INTRODUCTION}

In the 1970s, the presence of free 3-monochloro-1,2-propanediol (3-MCPD) was reported in food containing acidhydrolyzed vegetable protein and in the 1980s, 3-MCPD fatty acid esters (3-MCPD-Es) were found in food, albeit in trace amounts. The reports of Weisshaar (Germany) on the presence of 3-MCPD-Es (2007) and glycidol fatty acid esters (Gly-Es) (2009) in edible oils raised much concern in Europe $^{1,2)}$ because the hydrolysis of 3-MCPD-Es and Gly-Es in the body could release free 3-MCPD and glycidol (Gly). A number of studies on the dietary exposure to 3-MCPD-Es and Gly-Es, along with their analytical methods, have been conducted ${ }^{3,4)}$ but their toxicological consequences are not fully understood.

Direct and indirect methods for the analysis of 3-MCPDEs, 2-monochloro-1,3-propanediol fatty acid esters (2MCPD-Es), and Gly-Es in edible oils have been developed. In a direct analytical method, the sample is purified by solid-phase extraction and the individual analytes are then measured by liquid chromatography-mass spectrometer (LC-MS). Through a joint study by Japan Oil Chemists' Society (JOCS) and American Oil Chemists' Society (AOCS), a direct analytical method for Gly-Es was registered as the JOCS Standard Method for the Analysis of Fats, Oils, and Related Materials 2.4.13 ${ }_{-2013}^{5,6)}$. Meanwhile, a direct method for the analysis of 3-MCPD-Es has been reported by Yamazaki et $a l^{7)}$ and Hori et al. ${ }^{8)}$. These direct analytical techniques are suitable for the toxicological assessment of individual compounds and the elucidation of their formation mechanism; however, the preparation of numerous standard reagents is required.

Using indirect analytical methods, an individual ester analyte is cleavaged, the glycerol skeleton is derivatized, and then analyzed by gas chromatography-mass spectrometer(GC-MS). These methods have the advantage of providing the equivalent concentrations of 3-MCPD, 2-MCPD, and Gly by using fewer standard reagents. In 2013, AOCS registered Cd 29a, Cd 29b, and Cd 29c as indirect analytical methods, which use different ester cleavage conditions ${ }^{9-11}$. Cd 29a involves ester hydrolysis under acidic conditions, whereas in Cd 29b, the hydrolysis is performed under basic conditions. In both cases, however, long reaction times are required. In Cd 29c, the ester cleavage is carried out under alkaline conditions with short reaction times; however, this technique is unable to quantify $2-\mathrm{MCPD}$. Thus, there is a need for a rapid indirect analytical method that can quantify 3-MCPD, 2-MCPD, and Gly simultaneously.

Miyazaki et al. developed an analytical method based on the use of lipase for the cleavage of ester analytes in 0.5 $\mathrm{h}^{12)}$. To validate this method, we organized an MCPD subcommittee consisting of 13 laboratories in JOCS, with 4 of these laboratories conducting a preliminary study to identify possible rectifications in sample preparation and analysis procedures. As discussed in this report, we obtained good reproducibility from the subsequent feasibility study that was conducted by all 13 laboratories, based on an improved method resulting from the preliminary study.

\section{EXPERIMENTAL PROCEDURES}

\subsection{Reagents}

For the ester standard reagents added to the oil samples, which were distributed to the participating laboratories, glycidyl oleate was purchased from Wako Pure Chemical (Japan), whereas 3-MCPD dioleate and 2-MCPD dilinoleate were purchased from Toronto Research Chemicals (Canada). As for the free standard reagents, 3-MCPD and 3-MBPD were purchased from Wako Pure Chemical, 3-MCPD- $d_{5}$ from CDN Isotopes (Canada), 2-MCPD, $2-\mathrm{MCPD}-d_{5}$, and 3-MBPD- $d_{5}$ from Toronto Research Chemicals, and Lipase AYS Amano (derived from Candida rugosa) from Wako Pure Chemical. They were distributed to all the laboratories in the subcommittee. Phenylboronic $\operatorname{acid}(\mathrm{PBA})$ (purity $\geq 97 \%$ ) as well as special grade organic solvents and salts were purchased by the respective participating laboratories.

A $30 \%(\mathrm{w} / \mathrm{v})$ sodium bromide solution was adjusted to $\mathrm{pH}$ 5.0 with citric acid and disodium hydrogen phosphate. A sodium bromide solution containing $90 \mathrm{U} / \mathrm{mL}$ lipase was prepared by dissolving 3,600 U of Candida rugosa lipase in the $30 \%$ sodium bromide solution. A PBA solution was prepared by dissolving $1.25 \mathrm{~g}$ PBA in $10 \mathrm{~mL}$ water / acetone mixed solution $(1: 19, \mathrm{v} / \mathrm{v})$.

For the standard stock solutions, $300 \mu \mathrm{g} / \mathrm{mL}$ ethanol solutions were prepared for 2-MCPD, 3-MCPD, and 3-MBPD, whereas $200 \mu \mathrm{g} / \mathrm{mL}$ ethanol solutions were prepared for 2 -MCPD- $d_{5}, 3$-MCPD- $d_{5}$, and 3-MBPD- $d_{5}$ as internal standard stock solutions. On the day of the study, each standard stock solution was diluted with $30 \%$ sodium bromide aqueous solution to prepare $15 \mu \mathrm{g} / \mathrm{mL}$ standard mixed solutions I and $1.5 \mu \mathrm{g} / \mathrm{mL}$ standard mixed solutions II. Additionally, $2.0 \mu \mathrm{g} / \mathrm{mL}$ internal standard mixed solutions were prepared by diluting each of the internal standard stock solutions with ethanol.

\subsection{Sample preparation}

The oil samples were commercially available extra virgin olive (EVO) oil and palm oil (semi-solid and solid) at room temperature. Each oil was melted and added to the ester standard reagents. After undergoing sufficient agitation, they were dispensed into glass vials to obtain the homogeneously distributed oil samples (Table 1). The homogeneity of the distributed samples was confirmed by the coordinator (corresponding author). Oil samples Nos. 1-4 used in the preliminary study were preserved in the dark and refrigerated. Oil sample No. 5 used in the feasibility study was preserved in the dark at room temperature. 
Table 1 Test samples of preliminary and feasibility studies. Samples Nos. 2-5 were spiked with $3-4 \mathrm{mg} / \mathrm{kg}$ standards as free form equivalent concentration.

\begin{tabular}{|c|c|c|c|c|c|}
\hline \multirow{2}{*}{ No } & \multirow{2}{*}{ Study } & \multirow{2}{*}{ Oil } & \multicolumn{2}{|c|}{ Spiked standards } & \multirow{2}{*}{ Storage temp. } \\
\hline & & & Indication & Compound & \\
\hline 1 & \multirow[t]{4}{*}{ Preliminary } & Extra virgin olive ${ }^{a}$ & \multirow[t]{4}{*}{ Unindicated } & Blank & \multirow{4}{*}{$\begin{array}{l}\text { Refrigeration } \\
\left(5^{\circ} \mathrm{C}\right)\end{array}$} \\
\hline 2 & & Extra virgin olive $^{a}$ & & $\begin{array}{l}\text { 3-MCPD dioleate, } \\
\text { 2-MCPD dilinoleate, } \\
\text { and Gly oleate }\end{array}$ & \\
\hline 3 & & Palm (Semi-solid) ${ }^{\text {b) }}$ & & Gly oleate & \\
\hline 4 & & Palm (Solid) ${ }^{\mathrm{c})}$ & & $\begin{array}{c}\text { 3-MCPD dioleate } \\
\text { and 2-MCPD dilinoleate }\end{array}$ & \\
\hline 5 & Feasibility & Extra virgin olive $^{a}$ & Indicated & $\begin{array}{l}\text { 3-MCPD dioleate, } \\
\text { 2-MCPD dilinoleate, } \\
\text { and Gly oleate }\end{array}$ & $\begin{array}{l}\text { Room } \\
\left(25^{\circ} \mathrm{C}\right)\end{array}$ \\
\hline
\end{tabular}

Iodine values $(\mathrm{g} / 100 \mathrm{~g}): \mathrm{a}) 81.5, \mathrm{~b}) 51.8$, and c) 37.5 .

\subsection{Equipment}

A temperature-controlled water bath, a vortex mixer, a high-speed shaker, a centrifuge, a nitrogen gas sprayer, and a GC-MS were used for each laboratory. A typical running conditions were as follow: water bath, DH-12 (Taitec, Japan); vortex mixer, HM-10H(AS ONE, Japan); highspeed shaker, CM-1000(EYELA, Japan); centrifuge, Model 4000 (Kubota, Japan); nitrogen gas sprayer, EN-10/ DTU-1BN(Taitec, Japan); GC-MS, 5975 series GC/MSD (Agilent, USA).

\subsection{Procedure of oil sample and calibration curve}

The method developed by Miyazaki et al. ${ }^{12)}$ was modified and illustrated in Fig. 1. In a $10 \mathrm{~mL}$ test tube, $0.1 \mathrm{~g}$ of oil sample was dissolved in $200-500 \mu \mathrm{L}$ of isooctane. After adding $3 \mathrm{~mL}$ of $30 \% \mathrm{NaBr}$ aqueous solution containing 90 $\mathrm{U} / \mathrm{mL}$ lipase, the mixture was shaken by a high-speed shaker for $30 \mathrm{~min}$ at room temperature $\left(25^{\circ} \mathrm{C}\right.$, ester cleavage). The test tube was heated for $10 \mathrm{~min}$ in an $80^{\circ} \mathrm{C}$ water bath (bromination from Gly to 3-MBPD; in the preliminary study, heating was performed during PBA derivatization). The test tube was cooled to room temperature, and $50 \mu \mathrm{L}$ of $2.0 \mu \mathrm{g} / \mathrm{mL}$ internal standard mixed solution was added. Next, $3 \mathrm{~mL}$ of hexane was added and shaken for $10 \mathrm{~min}$. The resulting aqueous layer was transferred to a new test tube. Another $3 \mathrm{~mL}$ of hexane was added and the tube was shaken for $10 \mathrm{sec}$; the resulting hexane layer was subsequently removed. A $20 \mu \mathrm{L}$ PBA solution was added to the aqueous layer, and the mixture was agitated with a vortex mixer for $10 \mathrm{sec}$. Next, $3 \mathrm{~mL}$ of hexane was added and shaken for $10 \mathrm{sec}$. The resulting organic layer was transferred to a new test tube and concentrated to approximately $0.5-0.8 \mathrm{~mL}$ using a stream of nitrogen. After filtration through a $0.2 \mu \mathrm{m}$ membrane filter, the samples were subjected to GC-MS analysis.

To prepare the calibration curve solutions, the $1.5 \mu \mathrm{g} / \mathrm{mL}$ standard mixed solutions II were transferred in quantities of $5,20,50$, and $100 \mu \mathrm{L}$, whereas the $15 \mu \mathrm{g} / \mathrm{mL}$ standard mixed solutions I were transferred in quantities of 20,35 , 50 , and $70 \mu \mathrm{L}$, to $10 \mathrm{~mL}$ test tubes (resulting in 0.0075 , $0.030,0.075,0.15,0.30,0.53,0.75$, and $1.1 \mu \mathrm{g}$ of material in the respective test tubes). A mixture of $50 \mu \mathrm{L}$ of $2.0 \mu \mathrm{g} / \mathrm{mL}$ internal standard mixed solution and $3 \mathrm{~mL}$ of $30 \% \mathrm{NaBr}$ solution were added to these test tubes. PBA derivatization was performed as described above.

\subsection{GC-MS Measurement}

A GC capillary column with length $30 \mathrm{~m}$, internal diameter $0.25 \mathrm{~mm}$, and film thickness $0.25 \mu \mathrm{m}$ was used. Each laboratory individually decided on their preferred liquid phase of film from VF-5 or VF-17. The optional use of a guard column and a programed temperature vaporizer (PTV) function in the inlet depended on the participating laboratory. Helium served as a carrier gas at a fixed flow rate of $1.2 \mathrm{~mL} / \mathrm{min}$. The sample injection was performed in the splitless mode at a temperature of $250^{\circ} \mathrm{C}$. The column oven temperature was held at $60^{\circ} \mathrm{C}$ for $1 \mathrm{~min}$, increased at $10^{\circ} \mathrm{C} / \mathrm{min}$ to $60-150^{\circ} \mathrm{C}$, followed by $3^{\circ} \mathrm{C} / \mathrm{min}$ to $150-180^{\circ} \mathrm{C}$, and subsequently $30^{\circ} \mathrm{C} / \mathrm{min}$ to $180-300^{\circ} \mathrm{C}$, and finally held at $300^{\circ} \mathrm{C}$ for $8 \mathrm{~min}$ (total $32 \mathrm{~min}$ ). MS was performed in the positive electron ionization mode with an ion source temperature of $230^{\circ} \mathrm{C}$. Quantitative and qualitative analyses were performed by selective ion monitoring (SIM) using ions at $\mathrm{m} / \approx 147$ and 196 for the 3-MCPD derivative, 150 and 201 for the 3-MCPD- $d_{5}$ derivative, 196 and 198 for the 2-MCPD derivative, 201 and 203 for the 2 -MCPD- $d_{5}$ derivative, 147 and 240 for the 3-MBPD derivative, along with 150 and 245 for the 3-MBPD- $d_{5}$ derivative.

\subsection{Collaborative Studies}

The preliminary study was conducted to identify possible rectifications in sample preparation and analysis proce- 

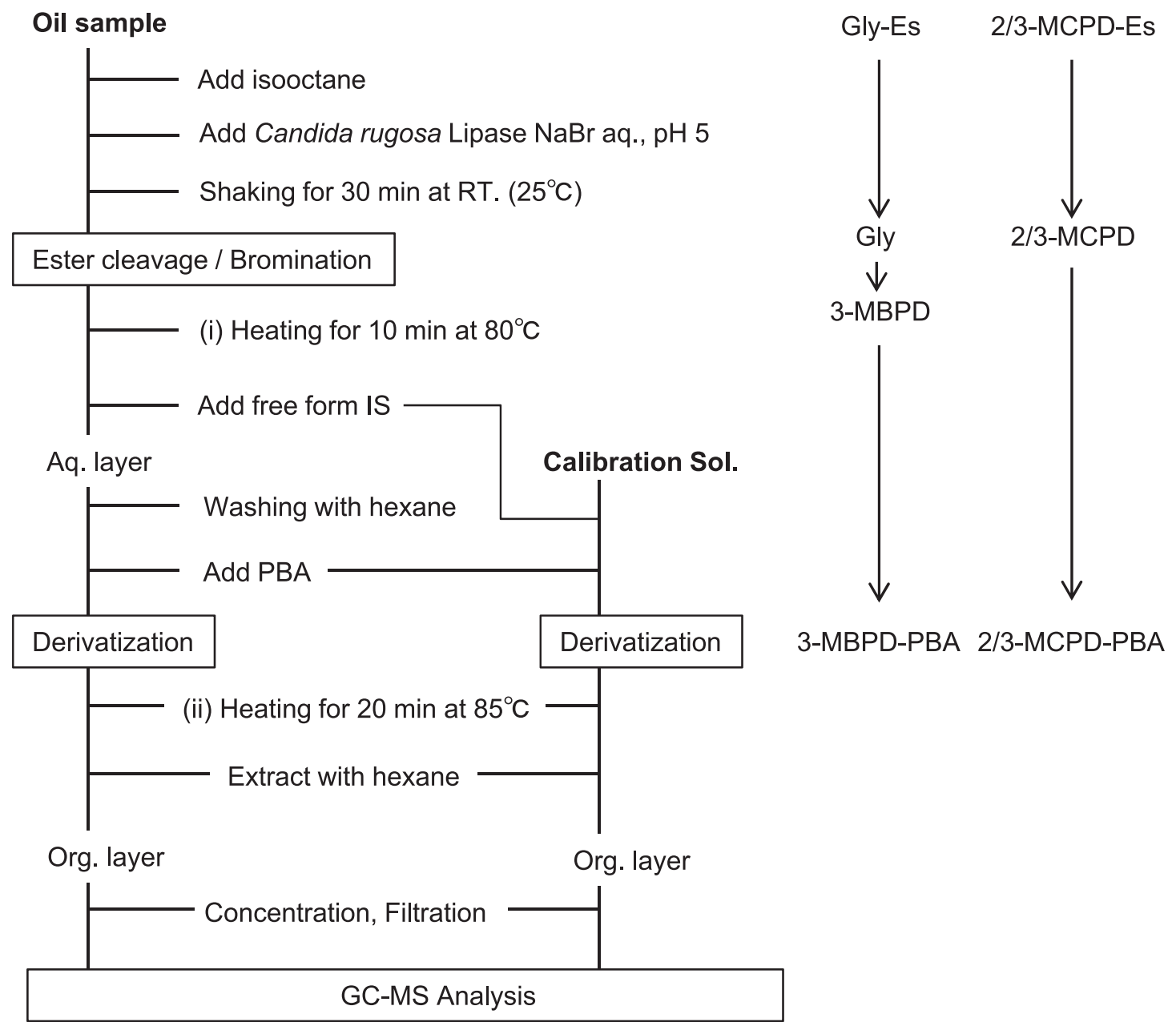

Fig. 1 Procedure flow of this analytical method. Heating procedure: (i) in modified procedure (feasibility study), (ii) original procedure (preliminary study).

dures. Sample Nos. 1-4 in Table 1 were distributed to 4 laboratories and analyzed twice by each laboratory. The problems observed in the preliminary study were corrected prior to the feasibility study. Sample No. 5 in Table 1 was distributed to 13 laboratories and analyzed twice by each laboratory.

Table 2 lists the high-speed shakers used by the participating laboratories as described in the procedures of Section 2.4: (i) horizontal eccentric shaker, (ii)vertical shaker with vertically placed test tubes, and (iii) horizontal shaker with test tubes tilted $60^{\circ}$ from a horizontal plane.

\section{RESULTS AND DISCUSSION}

\subsection{Preliminary Study}

3-MCPD, 2-MCPD, and Gly of EVO oil and palm oil samples were determined using the original procedure (Fig. 1 (ii)). Table 3 lists the results and the statistical parameters obtained by 4 laboratories. Blank EVO oil (sample No.
1) was omitted because no 3-MCPD, 2-MCPD, or Gly was detected. The relative standard deviations for inter-laboratory reproducibility $\left(\mathrm{RSD}_{\mathrm{R}}\right)$ of 3-MCPD, 2-MCPD, and Gly in EVO (sample No. 2), and of 3-MCPD and 2-MCPD in semisolid palm oil (sample No. 3), as well as solid palm oil (sample No. 4) were less than 10\%. After excluding the aberrant values, the amount of data for samples Nos. 3 and 4 was limited. This is because sample No. 4 from laboratory C was eliminated by Cochran's test, while laboratory D did not report the results of samples Nos. 3 and $4 . \mathrm{RSD}_{\mathrm{R}}$ value of Gly in semi-solid palm oil and solid palm oil were $79 \%$ and $13 \%$, respectively. We speculated that the wide range of reproducibility value was caused by the instability of samples during storage and by sensitive procedures such as the shaking conditions for ester cleavage.

Recoveries for all analytes are shown in Table 4. The recoveries of 3-MCPD and 2-MCPD were found to be in the range of $102-111 \%$ for EVO oil, semi-solid palm oil, and solid palm oil. The indirect method is based on the cleavage of ester analytes into their corresponding free analytes. 
Table 2 Conditions selected by 13 laboratories regarding of high-speed shaker of oil samples, isooctane, and the lipase solution.

\begin{tabular}{|c|c|c|c|c|c|}
\hline & \multicolumn{2}{|c|}{ Shaking condition } & \multirow{2}{*}{$\begin{array}{l}\text { Mounting angle } \\
\left(\left(^{\circ}\right)^{\mathrm{a})}\right.\end{array}$} & \multicolumn{2}{|c|}{ Participant lab. code } \\
\hline & Direction & $\begin{array}{l}\text { Speed } \\
(\mathrm{rpm})\end{array}$ & & $\begin{array}{l}\text { Preliminary } \\
\text { study }\end{array}$ & $\begin{array}{c}\text { Feasibility } \\
\text { study }\end{array}$ \\
\hline $\mathrm{i}$ & Eccentric orbit & 1,800 & 90 & $\mathrm{~A}, \mathrm{~B}$ & $\mathrm{~A}, \mathrm{~B}, \mathrm{E}, \mathrm{G}, \mathrm{J}, \mathrm{L}$ \\
\hline ii & Vertical reciprocating & 200 & 90 & $\mathrm{D}$ & $\mathrm{D}, \mathrm{F}, \mathrm{I}, \mathrm{K}, \mathrm{M}$ \\
\hline iii & Horizontal reciprocating & $200-400$ & 60 & $\mathrm{C}$ & $\mathrm{C}, \mathrm{H}$ \\
\hline
\end{tabular}

a) Test tube angle from horizontal on shaker.

There were concerns about the poor dispersibility of solid oil samples in an aqueous solution at room temperature and consequently, an incomplete ester cleavage in such a system. Additionally, 3-MCPD diester is the most difficult substrate to cleave among all the ester analytes studied ${ }^{12)}$. These results showed that this indirect method can also be used in an oil/water system at room temperature for solid oils.

\subsection{Optimization of Method}

The four procedures cited in the preliminary study were modified. Firstly, the test tubes were shaken during the ester cleavage reaction, and it was necessary to specify the conditions used for each type of high-speed shaker. Since the liposoluble ester analyte was catalytically reacted with a lipase aqueous solution, vigorous shaking of the $10 \mathrm{~mL}$ test tubes was required. However, there was a concern regarding the possibility of insufficient agitation depending on the high-speed shakers' mechanism of action. For example, during horizontal reciprocating shaking (Table 2 (iii)), which was the slowest among the three mechanisms of action, the mixing of the test tube solutions was insufficient when the test tubes were tilted at $0^{\circ}, 30^{\circ}$, and $90^{\circ}$ (measured from a horizontal plane) whereas tilting at $60^{\circ}$ gave a good result. Before performing the experiments, the participating laboratories were instructed to choose one of the three conditions shown in Table 2. In a multiple comparison test by Tukey's method, 3-MCPD exhibited a higher content by (iii) horizontal shaking (tilting at $60^{\circ}$ ) than by(i)horizontal eccentric shaking and(ii)vertical shaking, whereas 2-MCPD and Gly showed no difference in mean value with different shaking conditions.

Secondly, in order to accelerate the conversion of Gly to $3-\mathrm{MBPD}$, the reaction mixture was heated immediately after the ester cleavage in the presence of $\mathrm{NaBr}($ Fig. 1 (i)), whereas the heating step was originally performed after the addition of PBA. In indirect methods, there is a common side reaction that occurs during the hydrolysis and bromination of 3-MCPD-Es; resulting in the formation of 3-MBPD (as an artifact) and the overestimation of Gly$\mathrm{Es}^{13)}$. However, the formation of the side reaction was suppressed $<1 \%$ using our modified method, consisting of fewer reaction steps without removing the bromination step.

Thirdly, after the ester cleavage and bromination, unnecessary matter originating from the oil sample was removed together with the organic layer during hexane washing. In the preliminary study, the organic layer was removed by pipette, together with the gel originating from lipase, but many analysts considered this procedure cumbersome. Laboratory D could not analyze sample Nos. 3 and 4(Table 3), because the GC-MS measurement sequence was discontinued due to protein precipitation (presumably lipase) in the glass liner of the injector. In order to solve this problem, the aqueous layer containing the free analyte was transferred to a separate test tube and this step was able to minimize the build-up of residual gel during PBA derivatization.

Fourthly, it was observed in all 4 laboratories that the baseline of the GC-MS spectrum extended beyond a retention time of 15 min after elution of the 3-MCPD derivative at $m / \approx 147$. However, although the standard deviation increased slightly, there was no difference in mean value according to a t-test. According to a separate total ion current chromatogram (TICC), these findings could be attributed to the formation of glycerol, a PBA derivative product, in the aqueous layer, which could decrease the functionality of the GC-MS system. This phenomenon is common among indirect analytical methods. We plan to include an additional dehydration step to reduce the formation of PBA derivative products in future studies.

\subsection{Glycidol Depletion during the Storage of Oil Samples}

In the preliminary study, large $\mathrm{RSD}_{\mathrm{R}}$ of Gly were observed in palm oils (Table 3, Nos. 3 and 4). In a separate study conducted by a coordinator, the Gly content in refrigerated oil sample No. 3 decreased by $44 \%$ after 72 days, and by $36 \%$ in sample No. 4 after 70 days. We speculated that the wide range of reproducibility was caused by the cold storage of the palm oil samples as the storage period was different among the 4 laboratories and thus, conducted an additional low-temperature storage test of the palm oil samples.

Figure 2 shows the time course during which a solid 
Table 3 Results and statistical parameters by preliminary study obtained from 4 laboratories; sample No. 1 was blank extra virgin olive oil, and was omitted because it was less than the limit of determination.

\begin{tabular}{|c|c|c|c|c|c|c|c|c|c|c|c|}
\hline \multirow{4}{*}{ Statistical paramaters } & \multirow{3}{*}{\multicolumn{2}{|c|}{$\begin{array}{l}\text { Lab. code } \\
\text { Repetition }\end{array}$}} & \multicolumn{9}{|c|}{ Equiv. conc. (mg/kg) } \\
\hline & & & \multicolumn{3}{|c|}{ No.2, Extra virgin olive } & \multicolumn{3}{|c|}{ No.3, Palm (Semi-solid) } & \multicolumn{3}{|c|}{ No.4, Palm (Solid) } \\
\hline & & & \multirow{2}{*}{$\frac{3-\mathrm{MCPD}}{4.92}$} & \multirow{2}{*}{$\begin{array}{c}\text { 2-MCPD } \\
3.97\end{array}$} & \multirow{2}{*}{$\begin{array}{l}\text { Gly } \\
4.86\end{array}$} & \multirow{2}{*}{$\frac{3-\mathrm{MCPD}}{2.56}$} & \multirow{2}{*}{$\begin{array}{c}\text { 2-MCPD } \\
1.26\end{array}$} & \multirow{2}{*}{$\begin{array}{l}\text { Gly } \\
3.46\end{array}$} & \multirow{2}{*}{$\begin{array}{c}3 \text {-MCPD } \\
5.15\end{array}$} & \multirow{2}{*}{$\begin{array}{c}\text { 2-MCPD } \\
4.09\end{array}$} & \multirow{2}{*}{$\begin{array}{c}\text { Gly } \\
0.99\end{array}$} \\
\hline & A & 1 & & & & & & & & & \\
\hline & & 2 & 4.92 & 3.98 & 4.83 & 2.66 & 1.18 & 3.59 & 5.15 & 4.06 & 1.01 \\
\hline & B & 1 & 4.80 & 3.60 & 4.91 & 2.37 & 1.22 & 2.58 & 4.57 & 3.63 & 0.85 \\
\hline & & 2 & 4.47 & 3.62 & 4.76 & 2.29 & 1.20 & 2.59 & 4.43 & 3.63 & 0.82 \\
\hline & $\mathrm{C}$ & 1 & 4.78 & 3.78 & 4.40 & 2.52 & 1.30 & 0.29 & 3.35 & 3.18 & 0.59 \\
\hline & & 2 & 4.86 & 3.82 & 4.54 & 2.71 & 1.25 & 0.23 & 5.05 & 4.32 & 0.93 \\
\hline & $\mathrm{D}$ & 1 & 4.08 & 3.79 & 4.54 & 2.09 & 1.33 & 2.45 & - a) & $-{ }^{\text {a) }}$ & - a) \\
\hline & & 2 & 3.85 & 3.70 & 4.83 & $-{ }^{\text {a) }}$ & $-{ }^{\text {a) }}$ & $-{ }^{\text {a) }}$ & $-{ }^{\text {a) }}$ & $-{ }^{\text {a) }}$ & $-{ }^{\text {a) }}$ \\
\hline \multicolumn{3}{|c|}{ Total number of laboratories in given assay } & 4 & 4 & 4 & 3 & 3 & 3 & 2 & 2 & 2 \\
\hline \multicolumn{3}{|c|}{ Total number of values in given assay } & 8 & 8 & 8 & 6 & 6 & 6 & 4 & 4 & 4 \\
\hline \multicolumn{3}{|l|}{ Mean } & 4.59 & 3.78 & 4.71 & 2.52 & 1.24 & 2.13 & 4.83 & 3.86 & 0.92 \\
\hline \multicolumn{3}{|c|}{ Repeatability standard deviation $\left(\mathrm{SD}_{\mathrm{r}}\right)$} & 0.14 & 0.03 & 0.13 & 0.09 & 0.04 & 0.06 & 0.07 & 0.01 & 0.02 \\
\hline \multicolumn{3}{|c|}{ Repeatability relative standard deviation $\left(\mathrm{RSD}_{\mathrm{r}}\right)$} & 3.14 & 0.89 & 2.66 & 3.70 & 3.11 & 2.67 & 1.39 & 0.31 & 2.13 \\
\hline \multicolumn{3}{|c|}{ Reproducibility standard deviation $\left(\mathrm{SD}_{\mathrm{R}}\right)$} & 0.44 & 0.15 & 0.20 & 0.18 & 0.04 & 1.68 & 0.46 & 0.31 & 0.12 \\
\hline \multicolumn{3}{|c|}{ Reproducibility relative standard deviation $\left(\mathrm{RSD}_{\mathrm{R}}\right)$} & 9.64 & 4.07 & 4.15 & 7.05 & 3.53 & 79.1 & 9.61 & 8.12 & 12.7 \\
\hline \multicolumn{3}{|l|}{ Repeatability value (r) } & 0.41 & 0.10 & 0.35 & 0.26 & 0.11 & 0.16 & 0.19 & 0.03 & 0.06 \\
\hline \multicolumn{3}{|l|}{ Reproducibility value (R) } & 1.25 & 0.44 & 0.55 & 0.50 & 0.12 & 4.76 & 1.31 & 0.89 & 0.33 \\
\hline
\end{tabular}

a) Not reported.

Table 4 Recovery obtained by the preliminary and feasibility studies; calculated from mean value of all laboratories relative to added quantity.

\begin{tabular}{cccccr}
\hline \multirow{2}{*}{ No } & \multirow{2}{*}{ Study } & \multirow{2}{*}{ Oil } & \multicolumn{3}{c}{ Recovery (\%) } \\
\cline { 4 - 6 } & & 3-MCPD & 2-MCPD & Gly \\
\hline 2 & \multirow{2}{*}{ Preliminary } & Extra virgin olive & 109 & 107 & 103 \\
3 & & Palm (Semi-solid) & 108 & 103 & 51 \\
4 & & Palm (Solid) & 111 & 102 & 64 \\
\cline { 3 - 6 } 5 & Feasibility & Extra virgin olive & 97 & 95 & 107 \\
\hline
\end{tabular}

palm oil sample was preserved by a coordinator in the dark at frozen temperature $\left(-18^{\circ} \mathrm{C}\right)$, refrigeration temperature $\left(5^{\circ} \mathrm{C}\right)$, and room temperature $\left(25^{\circ} \mathrm{C}\right)$. The Gly content under refrigeration decreased by $33 \%$ during 84 days, but did not decrease at frozen or room temperature during the same period. Refrigeration may have damaged the Gly-Es in the solid palm oil sample although the mechanism is currently unknown. Although not depicted in the diagram, 3-MCPD and 2-MCPD contents in the solid palm oil sample did not show a notable decrease at any preservation temperature. In the case of rapeseed oil, soybean oil, rice bran oil, and semi-solid palm oil, preservation temperatures did not affect the contents of Gly as well as 3-MCPD, and 2-MCPD. It was concluded that the oil samples should be delivered and preserved at room temperature in the dark.

\subsection{Feasibility Study}

3-MCPD, 2-MCPD, and Gly of an EVO oil sample were determined using the modified procedure. The results and the statistical parameters obtained from the feasibility study conducted across 13 laboratories are shown in Tables 5 and 6 , respectively. $\mathrm{RSD}_{\mathrm{R}}$ were $4.4 \%$ for 3 -MCPD, $11.2 \%$ for 2-MCPD, and $6.6 \%$ for Gly. The result for Gly from laboratory G was eliminated by Cochran's test, whereas the data for 2-MCPD (though doubtful according to Dixon's test) was included in the overall results to give a high $\mathrm{RSD}_{\mathrm{R}}$. Although different conditions were used, these results were considerably better than the $\mathrm{RSD}_{\mathrm{R}}$ values (9-30\%) in the palm oil sample, with the same content measured by AOCS in a collaborative study using three indirect analytical methods ${ }^{14}$. As shown in Table 4, sample 


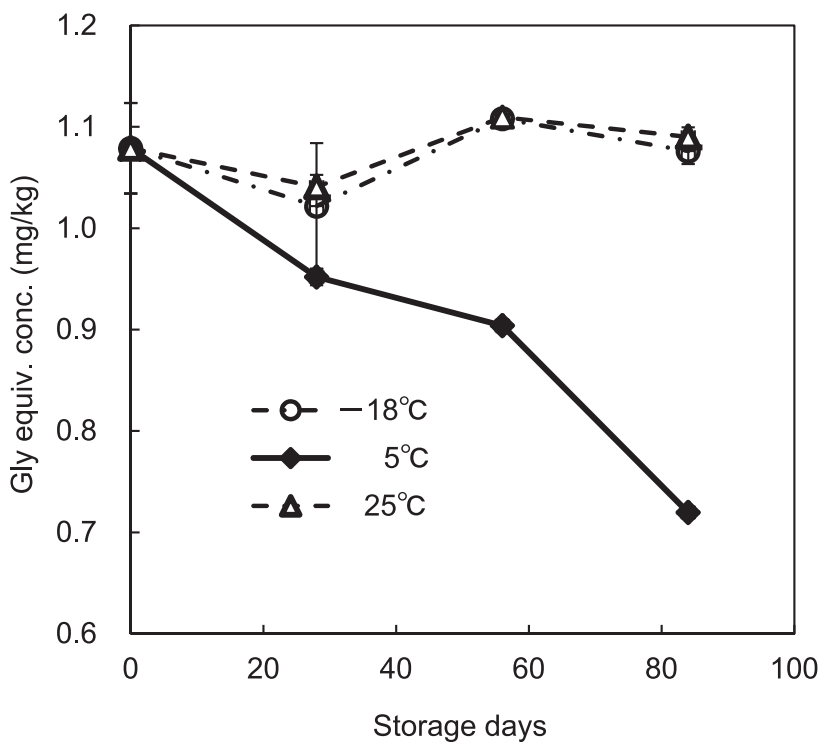

Fig. 2 Time course of Gly equivalent concentration in solid palm oil. Preservation temperature: $\bigcirc$ Frozen $\left(-18^{\circ} \mathrm{C}\right), \diamond$ Refrigerated $\left(5^{\circ} \mathrm{C}\right)$, and $\triangle$ Room temperature $\left(25^{\circ} \mathrm{C}\right)$. Error bars represent the SD of twice analyses.

No.5, the recoveries of 3-MCPD, 2-MCPD, and Gly were found to be in the range of $97-107 \%$ for an EVO oil. In this feasibility study, we can confirm that each participant had learned the procedure carefully, and previous problems with sample storage and analysis procedures had been rectified.

A multiple comparison test of GC-MS equipment manufacturers between Agilent, Shimadzu, and Thermo Scientific showed that only the mean value of 2-MCPD measured by an Agilent instrument was found to be lower than that measured by other instruments, whereas no difference was found in 3-MCPD or Gly levels.

The limit of quantification $(\mathrm{LOQ})$ was defined as $\mathrm{LOQ}=$ $7.2 \sigma / S$, where $\sigma$ is the standard deviation from five analyses of a $7 \mathrm{ng}$ analyte, and $S$ is the slope of eight data points on the calibration curve. In a separate study performed by a coordinator, the LOQ were $<2.1$ ng for $3-\mathrm{MCPD}$, 2-MCPD, as well as Gly $(<21 \mu \mathrm{g} / \mathrm{kg}$ in the case of $0.1 \mathrm{~g}$ of oil samples). The LOQ obtained by this method, depending on the GC-MS's sensitivity, were inferentially the same as that in reported by AOCS ${ }^{9-11,14)}$ and European Food Safety Authority $(\mathrm{EFSA})^{15)}$.

\section{CONCLUSIONS}

In this report, the preliminary and feasibility studies of an analytical protocol were conducted by a committee of 4 and 13 laboratories, respectively. We aim to verify the efficiency of an indirect, lipase-catalyzed ester cleavage
Table 5 Feasibility study results obtained from 13 laboratories.

\begin{tabular}{|c|c|c|c|c|}
\hline \multirow{3}{*}{ Lab. code } & \multirow{3}{*}{ Repetition } & \multicolumn{3}{|c|}{ Equiv. conc. (mg/kg) } \\
\hline & & \multicolumn{3}{|c|}{ No.5, Extra virgin olive } \\
\hline & & 3-MCPD & 2-MCPD & Gly \\
\hline \multirow[t]{2}{*}{ A } & 1 & 3.84 & 3.74 & 4.80 \\
\hline & 2 & 3.90 & 3.54 & 4.62 \\
\hline \multirow[t]{2}{*}{ B } & 1 & 4.23 & 4.27 & 5.03 \\
\hline & 2 & 3.88 & 4.01 & 4.91 \\
\hline \multirow[t]{2}{*}{$\mathrm{C}$} & 1 & 4.56 & 3.74 & 4.92 \\
\hline & 2 & 4.30 & 4.20 & 4.79 \\
\hline \multirow[t]{2}{*}{$\mathrm{D}$} & 1 & 4.28 & 3.69 & 4.28 \\
\hline & 2 & 4.21 & 3.65 & 4.32 \\
\hline \multirow[t]{2}{*}{$\mathrm{E}$} & 1 & 4.20 & 3.46 & 4.47 \\
\hline & 2 & 4.18 & 3.54 & 4.44 \\
\hline \multirow[t]{2}{*}{$\mathrm{F}$} & 1 & 3.83 & 3.59 & 4.39 \\
\hline & 2 & 3.96 & 3.61 & 4.66 \\
\hline \multirow[t]{2}{*}{ G } & 1 & 3.94 & 2.65 & - a) \\
\hline & 2 & 4.02 & 2.69 & - a) \\
\hline \multirow[t]{2}{*}{$\mathrm{H}$} & 1 & 4.27 & 3.60 & 4.60 \\
\hline & 2 & 4.18 & 3.54 & 4.51 \\
\hline \multirow[t]{2}{*}{ I } & 1 & 3.99 & 3.67 & 4.49 \\
\hline & 2 & 3.90 & 3.63 & 4.45 \\
\hline \multirow[t]{2}{*}{$\mathrm{J}$} & 1 & 4.32 & 3.47 & 4.63 \\
\hline & 2 & 4.00 & 3.27 & 4.36 \\
\hline \multirow[t]{2}{*}{ K } & 1 & 4.09 & 3.75 & 4.76 \\
\hline & 2 & 4.03 & 3.70 & 4.67 \\
\hline \multirow[t]{2}{*}{$\mathrm{L}$} & 1 & 4.20 & 3.90 & 4.36 \\
\hline & 2 & 4.22 & 3.80 & 4.27 \\
\hline \multirow[t]{2}{*}{$\mathrm{M}$} & 1 & 4.05 & 4.23 & 5.15 \\
\hline & 2 & 4.16 & 4.45 & 5.50 \\
\hline
\end{tabular}

a) Eliminated by Cochran's test.

method for the simultaneous analysis of 3-MCPD-Es, 2-MCPD-Es, and Gly-Es. In the preliminary study, the free equivalent concentrations of 3-MCPD and 2-MCPD in extra virgin olive oil, semi-solid palm oil, and solid palm oil were quantified. It was found that the cold storage of oil samples could affect the accuracy of quantification due to the instability of Gly in palm oil at refrigeration temperature $\left(5^{\circ} \mathrm{C}\right)$. After rectifying the problems related to sample storage and analysis procedures, the feasibility study carried out by 13 laboratories presented excellent $\mathrm{RSD}_{\mathrm{R}}$ values in extra virgin olive oil: $4.4 \%, 11.2 \%$, and $6.6 \%$ for $3-\mathrm{MCPD}$, 2-MCPD, and Gly, respectively. We plan to apply this newly developed method to the determination of 3-MCPD, 2-MCPD, and Gly in various oil samples in future studies. 
K. Koyama, K. Miyazaki and K. Abe et al.

Table 6 Statistical parameters by feasibility study obtained from 13 laboratories.

\begin{tabular}{lccc}
\hline \multirow{2}{*}{\multicolumn{1}{c}{ Statistical paramaters }} & \multicolumn{3}{c}{ No.5, Extra virgin olive } \\
\cline { 2 - 4 } & 3-MCPD & 2-MCPD & Gly \\
\hline Total number of laboratories in given assay & 13 & 13 & 12 \\
Total number of values in given assay & 26 & 26 & 24 \\
Mean & 4.11 & 3.67 & 4.64 \\
Repeatability standard deviation $\left(\mathrm{SD}_{\mathrm{r}}\right)$ & 0.12 & 0.13 & 0.12 \\
Repeatability relative standard deviation $\left(\mathrm{RSD}_{\mathrm{r}}\right)$ & 2.87 & 3.53 & 2.66 \\
Reproducibility standard deviation $\left(\mathrm{SD}_{\mathrm{R}}\right)$ & 0.18 & 0.41 & 0.31 \\
Reproducibility relative standard deviation $\left(\mathrm{RSD}_{\mathrm{R}}\right)$ & 4.37 & 11.2 & 6.62 \\
Repeatability value $(\mathrm{r})$ & 0.33 & 0.37 & 0.35 \\
Reproducibility value $(\mathrm{R})$ & 0.51 & 1.16 & 0.87 \\
\hline
\end{tabular}

\section{ACKNOWLEDGEMENT}

This study was carried by the committee of the standard methods of JOCS. The authors thank Dr. Masakazu Yamaoka, Dr. Yasushi Endo, and Mr. Yoshiaki Hirata for their helpful suggestions.

\section{References}

1) Weisshaar, R. Fatty acid esters of glycidol in refined fats and oils. Eur. J. Lipid Sci. Technol. 110, 183-186 (2008).

2) Weisshaar, R. Determination of total 3-chloropropane-1,2-diol(3-MCPD) in edible oils by cleavage of MCPD esters with sodium methoxide. Eur. J. Lipid Sci. Technol. 112, 158-165(2010).

3) Crews, C.; Chiodini, A.; Granvogl, M.; Hamlet, C.; Hrnčiřík, K.; Kuhlmann, J.; Lampen, A.; Scholz, G.; Weisshaar, R.; Wenzl, T.; Jasti, P. R.; Seefelder, W. Analytical approaches for MCPD esters and glycidyl esters in food and biological samples: a review and future perspectives. Food Addit. Contam. A 30, 11-45 (2012).

4) MacMahon, S.; Begleya, T. H.; Diachenko, G. W. Occurrence of 3-MCPD and glycidyl esters in edible oils in the United States. Food Addit. Contam. A 30, 20812092 (2013).

5) JOCS Standard Method for the Analysis of Fats, Oils and Related Materials (Japan Oil Chem. Soc. ed.), 2.4.13-2013 (2013).

6) Joint AOCS/JOCS Official Method (Am. Oil Chem. Soc. ed.), Cd 28-10 (2013).

7) Yamazaki, K.; Ogiso, M.; Isagawa, S.; Urushiyama, T.; Ukena, T.; Kibune, N. A new, direct analytical method using LC-MS/MS for fatty acid esters of 3-chloro-1,2- propanediol (3-MCPD esters) in edible oils. Food $A d$ dit. Contam. A 30, 52-68(2013).

8) Hori, K.; Koriyama, N.; Omori, H.; Kuriyama, M.; Arishima, T.; Tsumura, K. Simultaneous determination of 3-MCPD fatty acid esters and glycidol fatty acid esters in edible oils using liquid chromatography time-offlight mass spectrometry. LWT Food Sci. Technol. 48, 204-208 (2012).

9) AOCS Official Method(Am. Oil Chem. Soc. ed.), Cd 29a (2013).

10) AOCS Official Method (Am. Oil Chem. Soc. ed.), Cd $29 \mathrm{~b}(2013)$.

11) AOCS Official Method (Am. Oil Chem. Soc. ed.), Cd $29 \mathrm{c}(2013)$.

12) Miyazaki, K.; Koyama, K.; Sasako, H.; Hirao, T. Indirect Method for Simultaneous Determinations of 3-Chloro-1,2-Propanediol Fatty Acid Esters and Glycidyl Fatty Acid Esters. J. Am. Oil Chem. 89, 1403-1407 (2012).

13) Kuhlmann, J. Determination of bound 2,3-expoxy1-propanol (glycidol) and bound monochloropropanediol(MCPD) in refined oils. Eur. J. Sci. Technol. 113, 335-344 (2011).

14) Collison, M. W. Current status of MCPD and Glycidol Analysis in Oils in104th AOCS Annual Meeting, Montreal, presentation (2013).

15) Wenzl, T.; Samaras, V.; Giril, A.; Buttinger, G.; Karasek, L.; Zelinkova, Z. Development and validation of analytical methods for the analysis of 3-MCPD (both in free and ester form) and glycidyl esters in various food matrices and performance of an ad-hoc survey on specific food groups in support to a scientific opinion on comprehensive risk assessment on the presence of 3-MCPD and glycidyl esters in food. EFSA supporting publication EN-779 (2015). 